\title{
Process optimization design for jatropha-based biodiesel production using response surface methodology
}

\begin{abstract}
Biodiesel of non food vegetal oil origin is gaining attention as a replacement for current fossil fuels as its non-food chain interfering manufacturing processes shall prevent food source competition which is expected to happen with current biodiesel production processes. As a result, non edible Jatropha curcas plant oil is claimed to be a highly potential feedstock for non-food origin biodiesel. $\mathrm{CaOÏ} \mathrm{MgO}$ mixed oxide catalyst was employed in transesterification of non-edible J. curcas plant oil in biodiesel production. Response surface methodology (RSM) in conjunction with the central composite design (CCD) was employed to statistically evaluate and optimize the biodiesel production process. It was found that the production of biodiesel achieved an optimum level of $93.55 \%$ biodiesel yield at the following reaction conditions: 1) Methanol/oil molar ratio: 38.67, 2) Reaction time: 3.44 h, 3) Catalyst amount: $3.70 \mathrm{wt} \%$, and 4) Reaction temperature: $115.87{ }^{\circ} \mathrm{C}$. In economic point of view, transesterification of $\mathrm{J}$. curcas plant oil using $\mathrm{CaO} i ̈ \mathrm{MgO}$ mixed oxide catalyst requires less energy which contributed to high production cost in biodiesel production. The incredibly high biodiesel yield of $93.55 \%$ was proved to be the synergetic effect of basicity between the active components of $\mathrm{CaO}$ ï $\mathrm{MgO}$ shown in the physicochemical analysis.
\end{abstract}

Keyword: Optimization; CCD; RSM; Jatropha oil; Transesterification; Biodiesel 